\title{
Output energy maximization of a single axis photovoltaic solar tracking system: experimental verification
}

\author{
S. H. Chong, N. N. Chandren, C. R. Allan Soon \\ Center for Robotics and Automation, Faculty of Electrical Engineering, Universiti Teknikal Malaysia Melaka, Malaysia
}

\begin{tabular}{l}
\hline \hline Article Info \\
\hline Article history: \\
Received Aug 21, 2018 \\
Revised Dec 22, 2018 \\
Accepted Mar 6, 2019 \\
\hline
\end{tabular}

Keywords:

Hybrid system

Maximum output energy

Photovoltaic

Single axis tracking system

Solar energy

\begin{abstract}
Major depletion of fossil fuel and the increase of greenhouse gasses such as carbon dioxide, chloroflurocarbons (CFCs), hydroflurocarbon (HFCs), perflurocarbons (PFCs) and Sulphur hexafluoride (SF6) worldwide are the catalyst for the interest of many counties towards renewable energy. The rising cost of electricity due to higher demand and less resource also led to the renewable energy venture. One of the most famous renewable energy is solar energy. Unfortunately, renewable energies are dependent on environment conditions, too. One of the major problems that affect the output energy of the solar panel is the cloud shadowing problem. Photovoltaic solar and wind hybrid system is capable to reduce the effects of the cloud shadowing by harvesting two different energy resources. However, the availability of wind energy harvesting has shown its instability performance. In this work, the photovoltaic solar array of the laboratoryscale single axis solar tracking system to maximize the output energy of the solar panel is examined experimentally. The solar array is connected in series and parallel configurations, and is experimented under different particalshadowed conditions. The experimentation is done to develop a solar array that has a minimum effect towards this type of occurances. Experimental results proved that the parallel configured solar panel has showed less influence by the cloud shadowing as compared to the single one.
\end{abstract}

Copyright ( 2019 Institute of Advanced Engineering and Science. All rights reserved.

\section{Corresponding Author:}

S. H. Chong,

Center for Robotics and Automation, Faculty of Electrical Engineering,

Universiti Teknikal Malaysia Melaka,

Hang Tuah Jaya Melaka 76100, Malaysia.

Email: horng@utem.edu.my

\section{INTRODUCTION}

Countries across the globe are currently showing interest towards harvesting renewable energy resources. The rising consumption of energy and failing accessibility of natural resources such as fossil fuels are increasing the cost of electricity. Renewable energy resources such as solar and wind energy have enough potential to become an important source for power generation in the future due to encironmental, social and economical benefits [1]. However, the development and adoption of these energies for large scale energy generation sector has become a major challenge. A setback that is common to wind and solar resources is their unpredictable nature and dependence on weather and climate conditions.

Many researchers have devoted to minimize the influence of weather and climate conditions to the output energy production. Fortunately, the abovementioned problem can be partially overcome by the integration of two different resources together to form a hybrid system [2]. Instead of only using photovoltaic (PV) solar panel to generate electricity, wind energy is also used to harvest energy at the same time and the energy produced by the wind turbine is supplied to the load and the battery bank [3]. In 1994, Borowy and Salameh determined the wind speed distributions, solar irradiance distributions, and calculated the wind turbine and photovoltaic average output. In their research, they stressed that hybrid system allows reduction 
in battery size due to continuous supply from wind source [4]. Celik [5] analyzed an auto small scaled PV and wind hybrid for optimization purpose. The optimization and techno-economical analysis of autonomous PV and wind hybrid energy in comparison to single PV and wind systems was done. The results showed that the hybrid of PV solar and wind is techno-economically better compared to single wind system or single PV solar system. In 2010, Dihrab et al. used MATLAB to analyze the PV solar and wind hybrid system that powers 750 houses in Iraq which consume $30 \mathrm{~kW}$ per/day [6]. The total plant generates $6 \mathrm{MW}$, which $5 \mathrm{MW}$ is generated from the PV solar and $1 \mathrm{MW}$ is produced by the wind system. In 2015, Bhattacharjee and Acharya optimally harnessed the wind resource with support of solar energy through hybrid technology. In the study, hybrid optimization model for electrical renewable software was used and they introduced economic parameter and component sizing as well [7]. Table 1 compares the characteristics and advantages of the PV solar system and the hybrid of PV solar and wind systems. Although numbers of advantges of the hybrid system has been documented, the suitability of implementation of hybrid of solar and wind in Malaysia is reported less effective due to the wind instability condition. To develop a hybrid of solar and wind system, the wind speed has to be consistent and strong throughout the year. Low and inconsistent wind speed in Malaysia, especially Malacca, has stopped the applicability of the wind resource. Section 2 will present the findings to show the wind resource condition in Malaysia.

Table 1. Comparison between the PV solar system and the hybrid of PV solar and wind system

\begin{tabular}{ll}
\hline Photovoltaic solar system & Photovoltaic solar and wind hybrid system \\
\hline $\begin{array}{l}\text { Harvesting only one source of renewable energy which is the solar } \\
\text { energy from sunlight }\end{array}$ & $\begin{array}{l}\text { Harvesting two sources of renewable energy which would be } \\
\text { the wind energy and solar energy } \\
\text { Costs less that hybrid PV solar and wind system }\end{array}$ \\
$\begin{array}{l}\text { Coorer output energy performance and less techno-economical PV solar system } \\
\text { Better output energy performance and better techno- } \\
\text { economical }\end{array}$ & $\begin{array}{l}\text { Strength of one renewable source will overcome the weakness } \\
\text { of the other renewable source }\end{array}$ \\
Depends only on the strength of one renewable source & Complex system as compared to the PV solar system
\end{tabular}

The optimum of output energy collected from PV solar system depends mainly on the PV panels configurations. A number of solar panels that are connected either in series or parallel configurations are referred as solar array [8]. In the series array, the solar panels in the array are connected in series, whereas in parallel array, the solar panels in the array are connected in parallel. Weather conditions also influence the efficiency. Under certain cloud conditions, the changes can be dramatic and fast. Passing cloud results in power variation in the photovoltaic generator and the condition further worsens when there is large load demand. There are ten types of cloud pattern that can affect the PV output when they are shadowed. The clouds can be characterized hy its shape, size, speed, direction, optical transmission and optical properties where each cloud pattern permits a certain percentage of irradiance to penetrate it [9]. This paper, therefore, deals with the investigation on the impact of solar array connections in the changes of cloud conditions experimentally.

\section{LABORATORY SCALE SINGLE AXIS SOLAR TRACKING SYSTEM}

The laboratory-scale single axis solar tracking system that is used to be optimized has a scaled ratio of 462:1 as compared to the actual solar tracking plant [10]. Figure 1 shows laboratory-scale single axis solar tracking system that used in the experiment. The dimension of the solar panel is $450(1) \times 340(\mathrm{w}) \mathrm{mm}$ with maximum output power of $20 \mathrm{~W}$. The tracking system uses a poly-crystalline (p-si) type SOLARLAND solar panel (model: SLP-020-12). The tracking system is actuated by a DC geared motor (motor driver: L293D), and an encoder is used to determine the angle of rotation of the motor. This tracking system is integrated with the Arduino Mega 2560 controller. Fo the solar array configurations, a solar panel with model: SLP-010-12 is added. Table 2 presens the specifications of the solar panels SLP-020-12 and SLP-010-12.

To maximize the laboratory-scale solar tracking system, solar array is developed by increasing the number of solar panels. The solar array is developed to increase the rated output power two times higher as compared to the existing rated output power [10]. Two $10 \mathrm{~W}$ panels are chosen instead of one $20 \mathrm{~W}$ panel to develop the solar array, where it will bring the same maximum power current as the $20 \mathrm{~W}$ one. In order to make sure the existing actuator and gearbox could support the modification made. The calculation of torque produced is calculated.

Int J Pow Elec \& Dri Syst, Vol. 10, No. 3, Sep 2019 : 1655 - 1661 
The torque desired to rotate the solar panel is calculated:

$\tau=F \times d$

where $\tau$ denotes the summation of the couple moments $(\mathrm{Nm}), F$ represents the magnitude force $(\mathrm{N})$, and $d$ represents the perpendicular distance from the line of action of the force to the axis rotation $(\mathrm{m})$.

To calculate the magnitude of force, $F$ :

$F=m a$

where $m$ is the mass of body $(\mathrm{kg})$, and $a$ is the body acceleration $\left(\mathrm{ms}^{-2}\right)$.

A gearbox is mounted on the shaft of the DC motor to increase the rated torque in order to overcome.the friction coefficient and the surrounding coefficient such as wind effet. It consists of two gearheads which is 14 and 25 respectively with the DC motor torque, with an input torque of $0.07 \mathrm{Nm}$. To calculate the output torque of the geared motor:

$G=\frac{\tau_{\text {output }}}{\tau_{\text {input }}}$

where $G$ denotes to the gear ratio, $\tau_{\text {output }}$ represents the output torque produced by the gear head, and the $\tau_{\text {input }}$ is the input torque applied to the gear head. Therefore, the output torque, $\tau_{\text {output }}=14 \times 25 \times 0.07 \mathrm{Nm}$. If the torque from the additional panels with the existing panel is below the output torque, the DC geared motor would be able to support the additional weight and function as usual. Since the rotation point of solar panels are at the centre, the wights are divided half $(5.04 \mathrm{~kg} / 2=2.52 \mathrm{~kg})$. From the calculation, the torque desired to rotate the solar panel is $\tau=F \times d=24.7 \times 0.17=4.20 \mathrm{Nm}$. Thus the DC heared motor is able to support the additional weight and torque when extra two panels are added. Figure 2 shows the schemetic design of the solar array, with its dimensions.

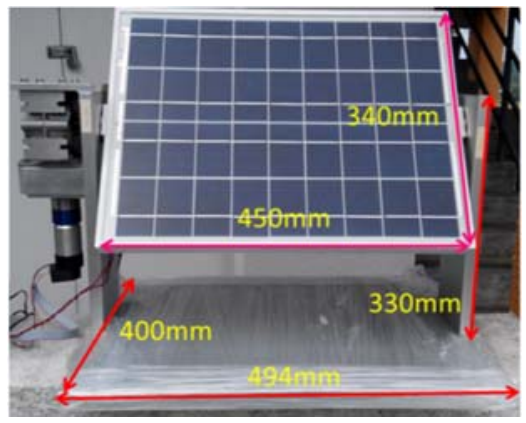

Figure 1. Laboratory-scale single axis solar tracking system

Table 2. Specifications of the solar panels SLP-020-12 and SLP-010-

\begin{tabular}{ccr}
\hline Specifications & SLP-020-12 & SLP-010-12 \\
\hline Maximum power (W) & 20 & 10 \\
Power tolerance (\%) & $\pm 3 \%$ & $\pm 3 \%$ \\
Maximum power voltage (V) & 18 & 18 \\
Maximum power current (A) & 1.12 & 0.56 \\
Open circuit voltage (V) & 22.2 & 22.2 \\
Short circuit current (A) & 1.27 & 0.6 \\
Maximum system voltage (V) & 1000 & 1000 \\
Cell efficiency (\%) & 16.8 & 16.8 \\
Module efficiency (\%) & 14.1 & 14.1 \\
Cells per module & 36 & 36 \\
Cell size & $76.5 \times 43$ & $52 \times 31.2$ \\
Temperature coefficient for power & -0.47 & -0.47 \\
$\left(\% /{ }^{\circ} \mathrm{C}\right)$ & \\
\hline
\end{tabular}




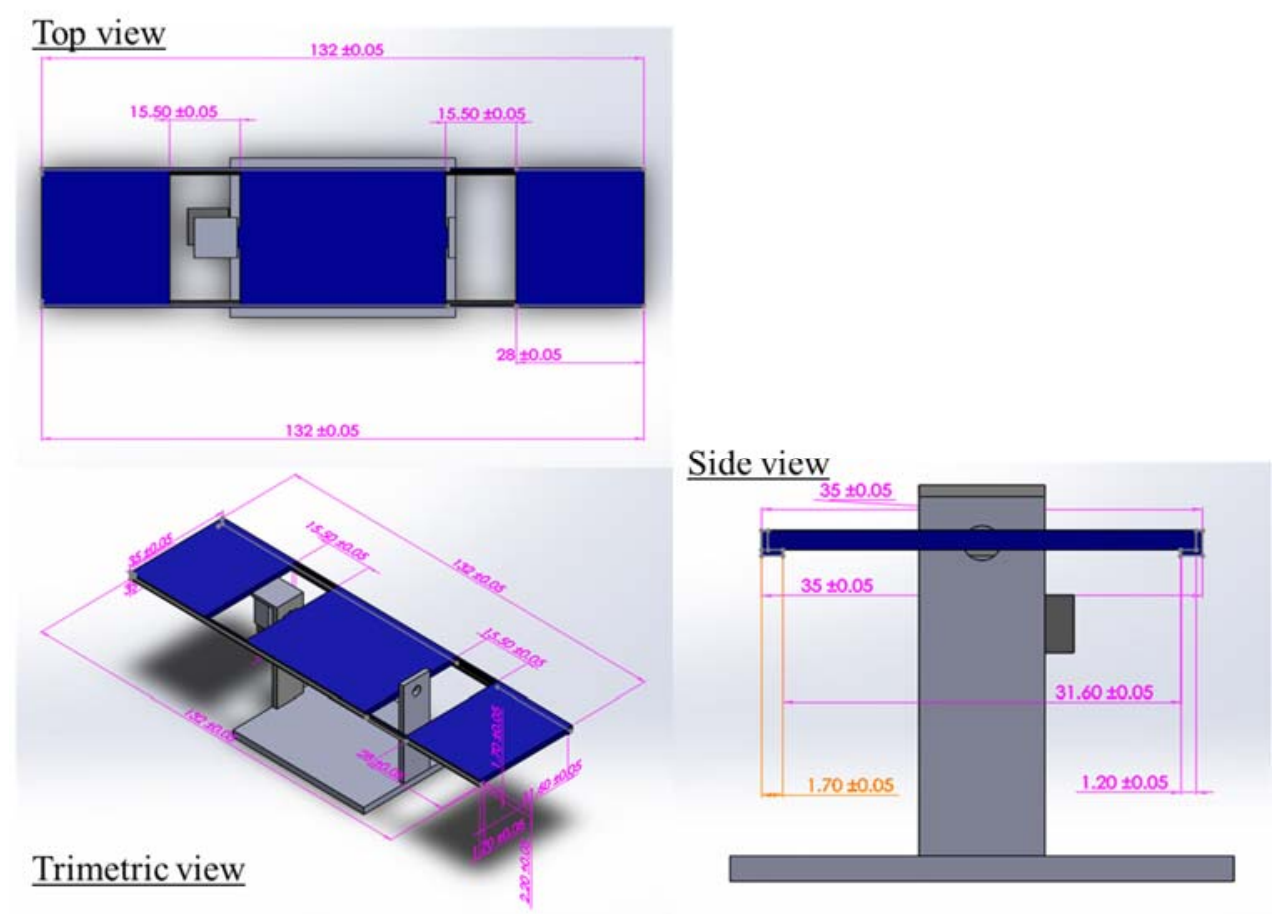

Figure 2. The schematic view of solar array

\section{RESULTS AND ANALYSIS}

In this section, it is explained the studies of possibilities of hybrid photovoltaic and wind system in Malaysia. Then, experiments are done to investigate the effect of cloud shadowing and solar panel configuration to the output energy generated.

\subsection{Studies of possibilities of hybrid photovoltaic and wind system in Malaysia}

Figure 3 illustrates the annual frequeyncy distribution of wind speds in Malaysia. Annual frequency distribution shows that the highest wind speed is around $2 \mathrm{~m} / \mathrm{s}$ to $4 \mathrm{~m} / \mathrm{s}$. In Melaka, the highest frequent wind speed is $2 \mathrm{~m} / \mathrm{s}$ which is $30 \%$ of the overall frequency. Figure 4 shows the annual mean wind speed in Melaka. As can be seen clearly that, the mean wind speed in Melaka is very low and light, which is not suitable to hybrid the solar and wind system, as wind energy needed as a starting torque to turn a turbines's blade is normally $2.5 \mathrm{~m} / \mathrm{s}$. Therefore, it can be conluded that, Melaka is not a suitable place to generate power using wind energy.

\subsection{Output energy optimization of the laboratory scale solar panel array}

The laboraotry scale single axis solar tracking system's output energy is maximized by developing a solar array. The solar array is arranged in two ways: series or parallel. In this section, the experiment is done to select the best configuration of solar panel that has lesser affect by the cloud shadowing and produce better output energy. The output power of the solar array is compared with the solar irradiance level to validate the irregular changes in output power. The experiment was done in campus of Universiti Teknikal Malaysia Melaka.

Figures 5 and 6 show the averaged output energy for five days, in the area of University's campus. Four condition of solar panel are investigated, which are normal (without shadowed), $10 \mathrm{~W}$ shadowed, $20 \mathrm{~W}$ shadowed, and $30 \mathrm{~W}$ shadowed. The solar arrays are examined in series and parallel configurations. The partial-shadowing cloud is created by using the sheer cloth (QPF 125) which is a semi-transparent material. According to the Tables 3 and 4 and Figures 5 and 6, the output power of the solar panel array is directly perpendicular to the solar irradiance level. As the solar irradiance increases, the output power of the solar panel array increases. The irregularity of solar irradiance is due to clouds in the sky, air humidity and wind. Solar irradiance data is used to validate the irregularity output power of the solar panel array. All the output power in this section is proven to be the cause of irregular solar irradiance level. 
From the partial shadowing findings, the parallel configuration is less affected by the shadowing condition. The output energy is reduced dramatically for series configuration as compared to the parallel one. The output energy reduction of the series configured solar panel array is higher because when one of the panel is shadowed, the current for the whole array is forced to be reduced to follow the output of the first shadowed panel. When one of the panel is shadowed, less photon current is produced but the solar array is forced to carry the same current as the panels that are not shadowed. The shadowed panel then begins to act as a load and causes reverse biased current draining the current from the panels that are not shadowed. This then contributes to the large drop when the first $10 \mathrm{~W}$ panel is shadowed. According to [8], [12], the same phenomenon occurs when the solar cells is shadowed partially. In contrast, the output energy only shows slightly decrement in parallel connected solar panel array because the reduction does not cause the other panels output energy generation.
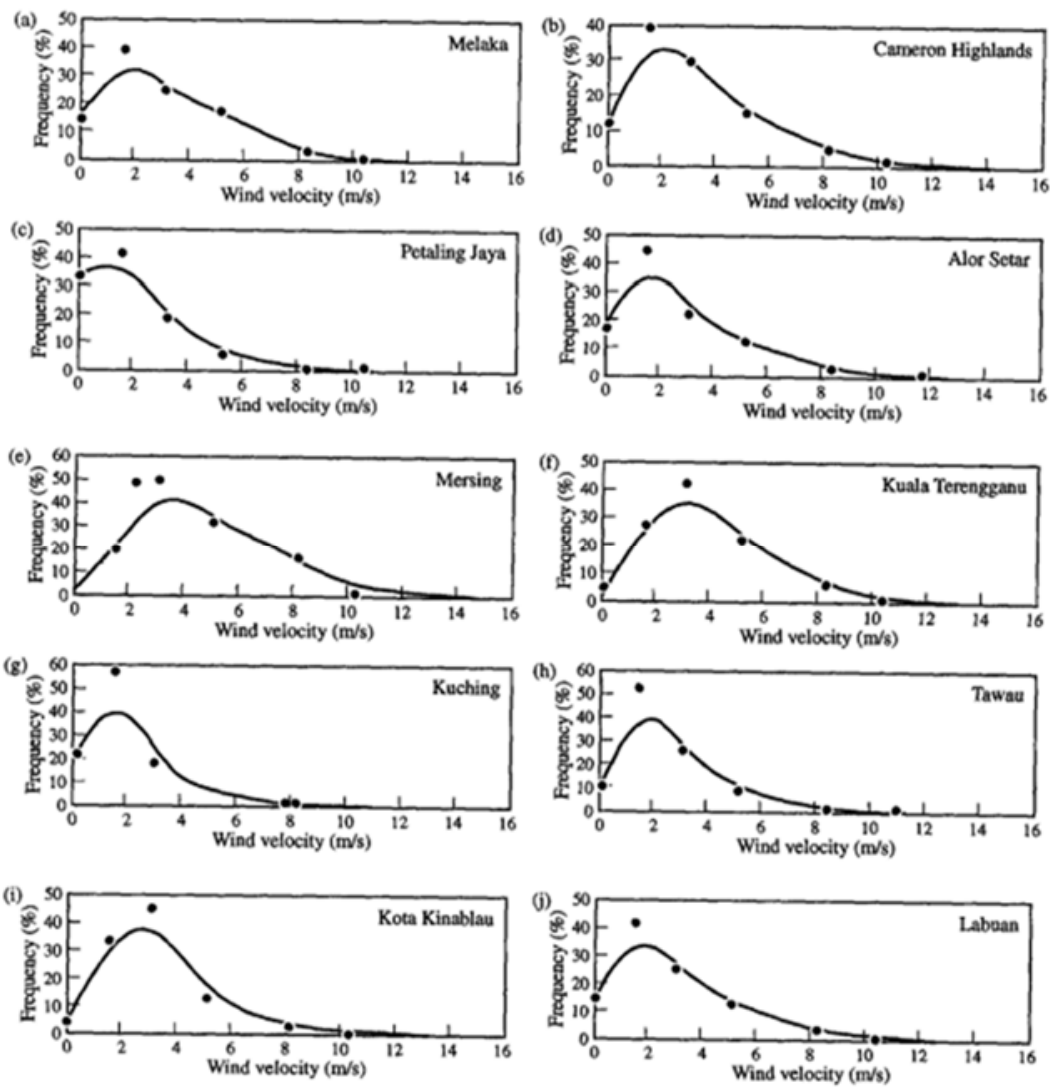

Figure 3. The annual frequency distribution of wind speeds in Malaysia [11]

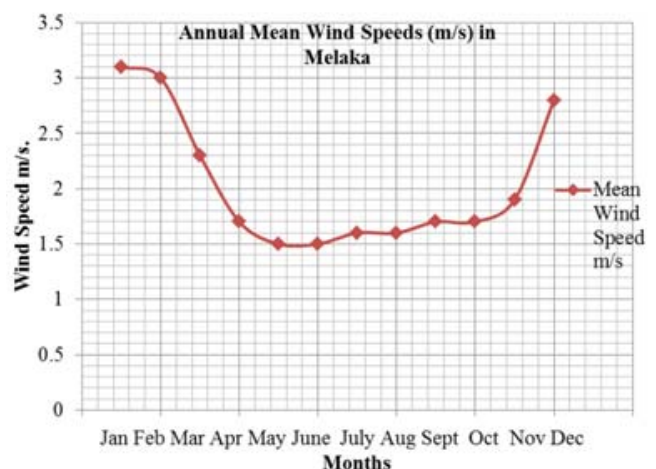

Figure 4. Annual mean wind speed in Melaka, Malaysia [11] 
Table 3. Averaged of output energy during normal and partial-shadowing condition - series configured solar array

\begin{tabular}{cccccc}
\hline $\begin{array}{c}\text { Time } \\
(\text { Hours })\end{array}$ & $\begin{array}{c}\text { Normal } \\
(\mathrm{W})\end{array}$ & $\begin{array}{c}10 \mathrm{~W} \text { shadowed } \\
(\mathrm{W})\end{array}$ & $\begin{array}{c}20 \mathrm{~W} \text { shadowed } \\
(\mathrm{W})\end{array}$ & $\begin{array}{c}30 \mathrm{~W} \text { shadowed } \\
(\mathrm{W})\end{array}$ & $\begin{array}{c}\text { Solar irradiance } \\
\left(\mathrm{W} / \mathrm{m}^{2}\right)\end{array}$ \\
\hline 1115 & 16.68 & 9.30 & 8.20 & 7.60 & 711.80 \\
1145 & 20.52 & 12.20 & 10.76 & 11.04 & 761.40 \\
1215 & 12.76 & 7.22 & 6.56 & 6.38 & 539.00 \\
1245 & 15.22 & 7.98 & 7.34 & 6.94 & 651.40 \\
1315 & 19.28 & 9.84 & 9.06 & 8.54 & 781.20 \\
1345 & 15.56 & 9.26 & 8.26 & 7.92 & 688.60 \\
1415 & 18.38 & 10.08 & 8.64 & 8.28 & 694.00 \\
\hline
\end{tabular}

Table 4. Averaged of output energy during normal and partial-shadowing condition - parallel configured solar array

\begin{tabular}{cccccc}
\hline $\begin{array}{c}\text { Time } \\
(\text { Hours })\end{array}$ & $\begin{array}{c}\text { Normal } \\
(\mathrm{W})\end{array}$ & $\begin{array}{c}10 \mathrm{~W} \text { shadowed } \\
(\mathrm{W})\end{array}$ & $\begin{array}{c}20 \mathrm{~W} \text { shadowed } \\
(\mathrm{W})\end{array}$ & $\begin{array}{c}30 \mathrm{~W} \text { shadowed } \\
(\mathrm{W})\end{array}$ & $\begin{array}{c}\text { Solar irradiance } \\
\left(\mathrm{W} / \mathrm{m}^{2}\right)\end{array}$ \\
\hline 1100 & 19.22 & 16.98 & 14.86 & 13.18 & 734.00 \\
1130 & 23.50 & 20.86 & 18.86 & 17.00 & 856.40 \\
1200 & 15.60 & 13.62 & 11.88 & 10.30 & 566.00 \\
1230 & 18.26 & 16.26 & 14.52 & 12.78 & 649.00 \\
1300 & 17.04 & 14.90 & 12.86 & 11.64 & 722.20 \\
1330 & 16.02 & 14.06 & 12.32 & 11.00 & 673.00 \\
1400 & 25.86 & 23.04 & 20.04 & 17.76 & 884.60 \\
\hline
\end{tabular}

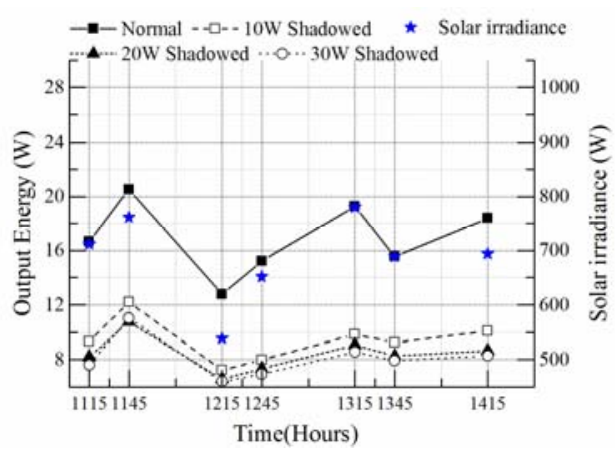

Figure 5. Comparative averaged experimental output energy of normal and shodowed conditions for series configuration solar panel

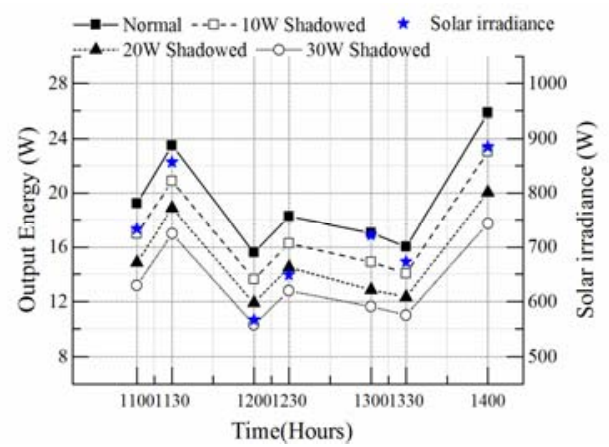

Figure 6. Comparative averaged experimental output energy of normal and shodowed conditions for parallel configuration solar panel

\section{CONCLUSION}

Renewable energy harvesting has high potential to become an important source for power generatio. In this research, the studies on possibilities of hybrid solar and wind system were done and due to the low and inconsistent of wind resources, Melaka is not suitable to have wind energy plant. Then, the optimization of output energy in cloud-free and cloud-shadowed condition was examined by using series and parallel solar panel arrangement. Experimetal evaluations were done in the campus of Universiti Teknikal Malaysia Melaka, and comparative analysis was showed. The results proved that the effect of cloud shadowing is severe as a sudden passage of cloud bank could sweep the entire photovoltaic generator and cause large power variation. However, the parallel arrangement of solar panel has reduced the effect of cloud shadowing on its generation of output energy.

\section{ACKNOWLEDGEMENTS}

The authors would like to be obliged to Motion Control Research Laboratory, Center for Robotics and Automation, Faculty of Electrical Engineering, Universiti Teknikal Malaysia Melaka for providing the laboratory facilities and equipment support. The project is funded by a research grant provided by Universiti Teknikal Malaysia Melaka (PJP/2017/FKE/HI11/S01533). 


\section{REFERENCES}

[1] M. Eroglu, et al., "A mobile renewable house using PV/ wind/ fuel cell hybrid power system," International Journal of Hydrogen Energy, vol. 36, no. 13, pp. 7985-7992, July 2011.

[2] F. Giraud, et al., "Analysis of The Effects of a Passing Cloud on a Grid-Interative Photovoltaic system with Battery Storage using Neural Networks," IEEE Transaction on Energy Conversion, vol. 14, no. 4, pp. 1572-1577, Dec 1999.

[3] Z. M. Salameh, et al., "Methodology for Optimally Sizing the Combination of a Battery Bank and PV Array in a Wind/PV.Hybrid System" IEEE Transaction on Energy Converstion, vol. 11, no. 2, pp. 367-375, June 1996.

[4] B. S. Borowy, et al., "Optimum PV Array Size for a Hybrif Wind/PV System," IEEE Transactions on Energy Conversion, vol. 9, no. 3, pp. 482-488, Sept 1994.

[5] A. N. Celik, et al., "Optimization and Techno-Economic Analysis of Autonomous PV-Wind Hybrid Energy System in Comparison to Single PV and Wind Systems," Energy Conversion and Management, vol. 43, no. 18, pp. 2453-2468, Dec 2002.

[6] S. S. Dihrab, et al., "Electricity Generation of PV/Wind Systems in Iraq," Renewable Energy, vol. 35, no. 6, pp. 1303-1307, June 2010.

[7] S. Bhattacharjee, et al., "PV-Wind Hybrid Power Option for a Low Wind Topology," International Nuclear Indotmation System, vol. 49, no. 39, pp. 942-954, 2015.

[8] R. Ramabadran, "Effects of Shading on Series and Parallel Connected Solar PV Modules," Modern Applied Science, vol. 3, no. 10, pp. 32-42, Oct 2009.

[9] W. Jewell, et al., "The Effects of Moving Clouds on Electric Utilities with Dispersed Photovoltaic Generation," IEEE Transaction on Energy Conversion, vol. EC-2, no. 4, pp. 570-576, Dec 1987.

[10] C. R. Allan Soon, et al., "laboratory-Scale Single Axis Solar Tracking System: Design and Implementation," International Journal of Power Electronics and Drive System (IJPEDS), vol 7, no. 1, pp. 254-264, March 2016.

[11] K. Sopian, et al., "The Wind Energy Potential of Malaysia," Renewable Energy, vol. 6, no. 8, pp. 1005-1016, Nov 1995

[12] B. A. Yount, et al., "Quantifying Insolation in Multiple Shading Scenarios," in 2011 IEEE Green Technologies Conference, pp. 1-6, 2011.

\section{BIOGRAPHIES OF AUTHORS}

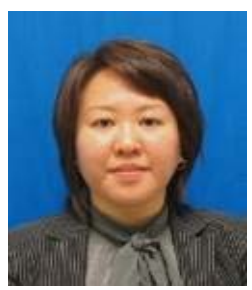

S. H. Chong received her B. Eng and M. Sc. in Electrical Engineering from the Universiti Teknologi Malaysia (UTM), Malaysia in 2001 and 2003 respectively. In year 2010, she received her Doctor of Engineering in Mechano-Micro Engineering from Tokyo Institute of Technology (Tokyo Tech), Japan. She is currently an Associate Professor in the Department of Control, Instrumentation and Automation, Faculty of Electrical Engineering, Universiti Teknikal Malaysia Melaka (UTeM). Her research interests include motion control, smart manufacturing IR4.0, mechatronic systems design and modelling, precision engineering, and rehabilitation system. She is founding member and secretary of Malaysian Society of Automatic \& Control Engineers (MACE) - IFAC NMO. She is the member in IFAC Technical Committee Control Design (IFAC TC 2.1), and Mechatronics (IFAC TC 4.2), too.

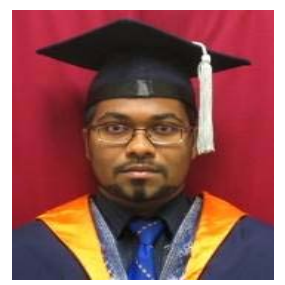

N.N Chandren was with the Motion Control Research Group, Faculty of Electrical Engineering, Universiti Teknikal Malaysia Melaka.

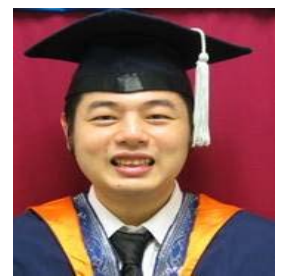

C.-R. Allan Soon was with the Motion Control Researh Group, Faculty of Electrical Engineering, Universiti Teknikal Malaysia Melaka. 